\title{
Circularised 1 and 2 LTR DNA circles are present in freshly- and chronically-infected cell lines and patient PBMCs, indicating ongoing reverse transcriptase usage
}

\author{
James M Fox ${ }^{1 *}$, Silva Hiburn², Lucy B M Cook ${ }^{3}$, Maria Antonietta Demontis ${ }^{2}$, Aileen Rowan ${ }^{3}$, Fabiola Martin ${ }^{1 *}$, \\ Graham P Taylor ${ }^{2}$
}

From 15th International Conference on Human Retroviruses: HTLV and Related Viruses

Leuven and Gembloux, Belgium. 5-8 June 2011

\section{Background}

After cell entry, HTLV-1 RNA is reverse transcribed and integrated into the host genome using its own reverse transcriptase (RT) and integrase (IN) enzymes. However, some unintegrated DNA circularises into 1 or 2 LTR DNA. Little is known about these unintegrated HTLV-1 DNA circles. Similar to HIV an inhibition of RT should decrease, and an inhibition of IN increase the 1/2 LTR DNA levels.

\section{Questions}

Can 1/2 LTRs be detected in chronically infected MT2 cells and patient samples? Can $1 / 2$ LTRs be detected in freshly infected CEM cells? Are 1/2 LTRs a marker of RT and IN activity? Can raltegravir (RGV), an IN inhibitor, prevent fresh infection?

\section{Methods}

Detection of 1/2 LTRs in MT2 cells and patient PBMCs (4 ATLL, 4 HAM/TSP, 4 AC) using nested PCRs. Coculture of gamma-irradiated MT2 with uninfected CEM cells with and without $1 \mu \mathrm{M}$ RGV for 2 weeks. DNA was extracted from $1 \times 10^{6}$ cells at days $3,7,10$ and 14 for proviral load and $1 / 2$ LTR DNA detection and quantification.

\section{Results}

1/2 LTRs were detected in MT2 (1LTR: 1 copy/600; 2LTR: 1copy/2000 cells); in all 16 patient PBMCs; in $3 \mathrm{hr}$ and day 14 infected CEM cells. Data on 1/ 2 LTR quantification in all patients and RGV inhibition study will be available for presentation.

\section{Conclusion}

Both 1 and 2 LTRs are detected in freshly (CEM) and chronically infected cells (MT2, patient PBMCs), indicating ongoing usage of RT. 2 LTR DNA circles are detected at significantly lower levels than 1 LTRs in MT2 cells.

\section{Author details \\ ${ }^{1}$ Centre for Immunology and Infection, Hull York Medical School and Department of Biology, University of York, York, UK. ${ }^{2}$ Section of Infectious Diseases, Imperial College, London, W2 1PG, UK. ${ }^{3}$ Department of Immunology, Imperial College, London, W2 1PG, UK.}

Published: 6 June 2011

\section{doi:10.1186/1742-4690-8-S1-A51}

Cite this article as: Fox et al:: Circularised 1 and 2 LTR DNA circles are present in freshly- and chronically-infected cell lines and patient

PBMCs, indicating ongoing reverse transcriptase usage. Retrovirology 2011 8(Suppl 1):A51.

\footnotetext{
* Correspondence: fabiola.martin@hyms.ac.uk

${ }^{1}$ Centre for Immunology and Infection, Hull York Medical School and

Department of Biology, University of York, York, UK

Full list of author information is available at the end of the article
}

(c) 2011 Fox et al; licensee BioMed Central Ltd. This is an open access article distributed under the terms of the Creative Commons Attribution License (http://creativecommons.org/licenses/by/2.0), which permits unrestricted use, distribution, and reproduction in any medium, provided the original work is properly cited. 